\title{
Colorectal cancer in the north and south of Ireland 1950-1984
}

\author{
F Kee, C Patterson, B Collins
}

\begin{abstract}
Study objective-Northern Ireland has the highest standardised mortality ratios for colon cancer in the United Kingdom and the Republic of Ireland has some of the highest mortality rates for cancer in the world. The aim of the study therefore was to investigate trends in colorectal cancer in the north and south of Ireland over the period 1950 to 1984.

Design-The study was a cohort analysis of deaths from colorectal cancer for ages 35-74 years by five year age groups, divided by sex.

Setting-This was a population study involving all cases reported to the Registrar General of Northern Ireland and the Eire Vital Statistics and Central Statistical Office during the study period.

Measurements and main results-As in mainland Britain, rectal cancer mortality declined in the north and the south during the study period, but the fall began sooner for males than females. Colon cancer mortality fell in the late 1950s but subsequently rose to its previous high levels.

Conclusions-The observation that there were declines in mortality in the north and south of Ireland in the late 1950 s does not support the hypothesis that altered diet due to war rationing in Great Britain and Northern Ireland underlay the fall in British colon cancer mortality after the war. The very high standardised mortality ratios for colon cancer in Northern Ireland highlight a continuing major public health problem in the region.
\end{abstract}

Mortality from colorectal cancer in the British Isles has changed considerably during this century. There have been important declines in age standardised death rates in England, Wales and Scotland. ${ }^{1-3}$ Though broadly parallel trends have emerged, the mortality rate in Scotland has remained higher than in England and Wales for 70 years. ${ }^{4}$ Northern Ireland has the highest standardised mortality ratios for colon cancer within the United Kingdom ${ }^{5}$ (fig 1), and the Republic of Ireland shares with New Zealand some of the highest national mortality rates in the world. ${ }^{6} 7$

Variations in mortality over the last 30 years in Northern Ireland have not previously been reported, but trends have been highlighted in the Republic of Ireland. ${ }^{78}$ Notably, colon cancer mortality in both sexes rose significantly between 1950 and $1982,{ }^{8}$ with an apparent plateau and slight decline after the mid 1970 s. $^{7}$ However, although allowance may be made for a changing age structure in the population by age standardisation, the interpretation of trends may be complicated by the presence of cohort effects. That such effects may be important in colorectal cancer has already been shown in England and Wales. $^{3}$

The present paper describes the time trends in colorectal cancer mortality for Ireland as a whole between 1950 and 1984 and findings are contrasted with the epidemiological data from mainland Britain.

\section{Methods}

For each year in the 1950-84 period, for ages between 35-74 years, numbers of deaths from cancer of the colon (ICD 153) and rectum (ICD 154) and age and sex specific mid-year population estimates (in five year age groups) were abstracted from the Annual Reports of the Registrar General of Northern Ireland, from the Eire Annual Reports on Vital Statistics and Central Statistical Office, Dublin, and from unpublished data on certain revisions from both of these sources. The total population of Northern Ireland over this time was approximately 1.5 million and of the south, approximately 3 million.

The changes in death rates over the period are displayed graphically, using directly age standardised mortality rates for the seven consecutive quinquennia between 1950-84, standardising to the world population structure. ${ }^{9}$ Standardised rates for England and Wales are shown for comparison.

The effects of age, period at death, and birth cohort on mortality rates have been investigated for each disease and sex, by using the age-periodcohort modelling approach ${ }^{10}$ for all deaths between 35 and 74 years. Briefly, the significance of age, period, and cohort effects may be assessed by fitting a series of nested models and using the changes in goodness of fit to obtain likelihood ratio $\chi^{2}$ statistics. Older age groups were not included because of the doubt about the coded cause of death in the very old.

\section{Results}

Figures 2 to 5 show the time trends in colorectal cancer in Ireland and England and Wales during the 1950-84 period. Important differences emerge between diseases, between the sexes, and to some extent between countries. Figures 2 and 3 show that, although death rates from colon cancer in 1950 differed little in the three regions, a marked differential in mortality between Ireland 
Figure 1 Female (a) and male (b) standardised mortality ratios of UK Home Countries 1984 (colon carcinoma).

Figure 2 Trends in age standardised colon cancer mortality in the British Isles 1950-84 (males 35-74 years)
Figure 3 Trends in age standardised colon cancer mortality in the British Isles (females 35-74 years)
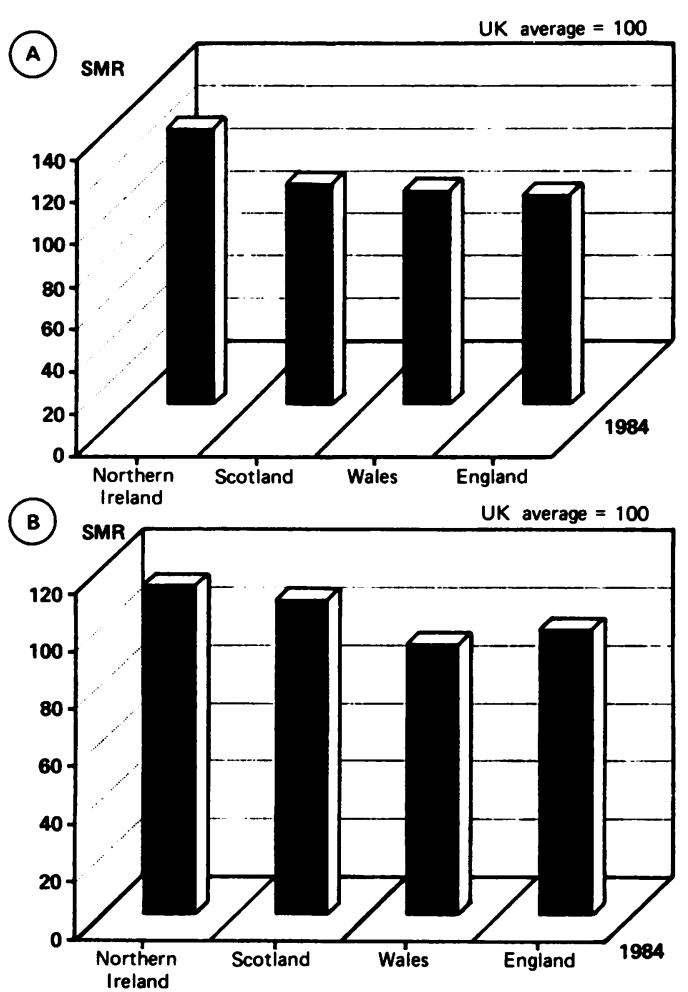

and England and Wales had emerged by $1980-84$. Ireland as a whole, in keeping with England and Wales, showed some decline in mortality during the 1950s, perhaps more marked among males, but by the early 1960 s mortality rose in an almost parallel fashion in the north and south of Ireland. In females, mortality appears to plateau and then decline slightly in the early 1980 s.

For rectal cancer figs 4 and 5 indicate that the mortality in Ireland and England and Wales has shown broadly comparable declines over the study period. In Northern Ireland, declines in
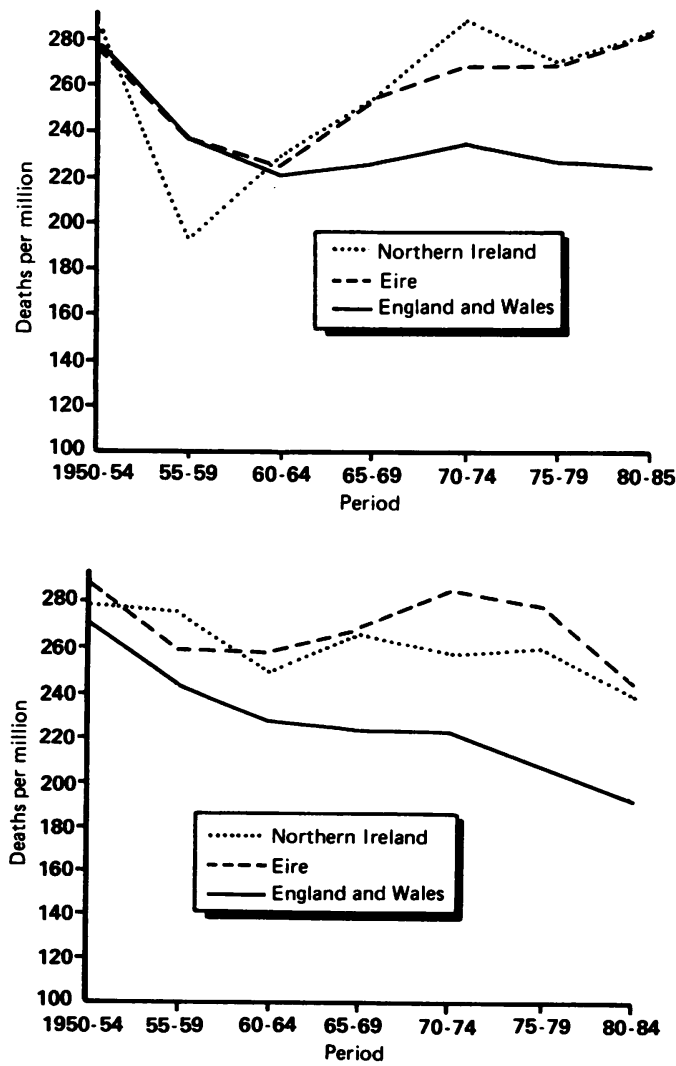

rates among females began somewhat later than in the other countries.

Likelihood ratio $\chi^{2}$ tests obtained from fitting various models to the Irish data are shown in the table.

\section{COLON CANCER}

The first line of the table indicates that, for males, period effects were significant when added to the model containing terms for age. Only for males in the Republic were cohort effects significant (line 2 ). In Northern Ireland males, line 3 shows that period effects persisted after adjustment for cohort. In the Republic there was significant lack of fit in the full age-period-cohort model, and the period and cohort effects in lines 3 and 4 were no longer significant when adjusted for extra Poisson variation. ${ }^{11}$ For Republic of Ireland males, secular trends could therefore be explained equally well by either period or cohort effects, but for Northern Ireland males period effects were clearly preferable.

There was no evidence of significant period or cohort effects for females either in Northern Ireland or in the Republic.

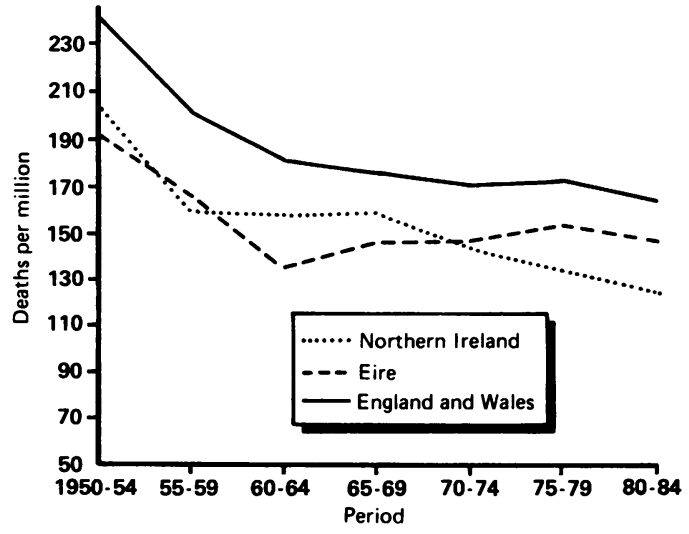

Figure 4 Trends in age standardised rectal cancer mortality in the British Isles (males 35-74 years)

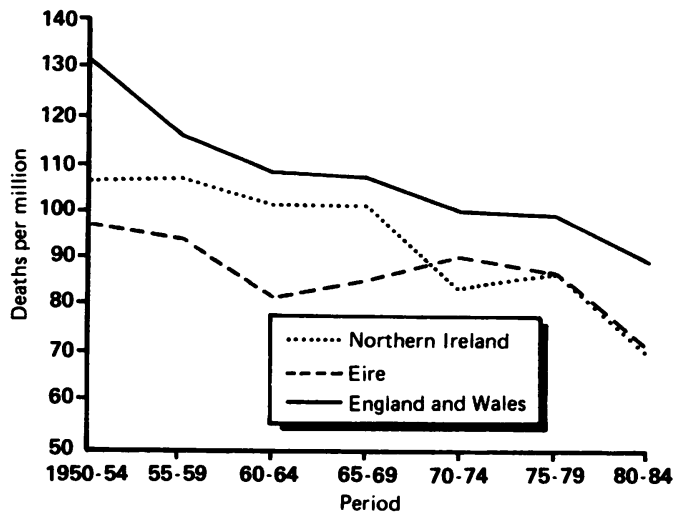

Figure 5 Trends in age standardised rectal cancer mortality in the British Isles (females 35-74 years).

RECTAL CANCER

Lines 1 and 2 of the table show that, for males and females, both period and cohort effects were significant when added to the model containing terms for age. When period effects were adjusted for age and cohort (line 3), only the Republic of Ireland male results maintained their 
Table Likelihood ratio $\chi^{2}$ tests for period and cohort effects ${ }^{a}$

\begin{tabular}{|c|c|c|c|c|c|}
\hline \multirow[t]{2}{*}{ Effect } & \multirow{2}{*}{$\begin{array}{l}\text { Degrees of } \\
\text { freedom }\end{array}$} & \multicolumn{2}{|c|}{ Northern Ireland } & \multicolumn{2}{|c|}{ Republic of Ireland } \\
\hline & & Males & Females & Males & Females \\
\hline \multicolumn{6}{|l|}{ Colon } \\
\hline $\begin{array}{l}\text { Period/Age } \\
\text { Cohort/Age } \\
\text { Period/Age, Cohort } \\
\text { Cohort/Age, Period }\end{array}$ & $\begin{array}{r}6 \\
12 \\
5 \\
12\end{array}$ & $\begin{array}{l}14 \cdot 6^{\star} \\
10 \cdot 9 \\
11 \cdot 2^{\star} \\
7 \cdot 5\end{array}$ & $\begin{array}{r}12 \cdot 3 \\
17 \cdot 6 \\
7 \cdot 4 \\
12 \cdot 8\end{array}$ & $\begin{array}{l}30 \cdot 9 \ddagger \\
38 \cdot 3 \ddagger \\
14 \cdot 2^{\star} \# \\
21 \cdot 6^{\star} \#\end{array}$ & $\begin{array}{l}12 \cdot 1 \\
13 \cdot 1 \\
10 \cdot 8 \\
11 \cdot 8\end{array}$ \\
\hline \multicolumn{6}{|l|}{ Rectum } \\
\hline $\begin{array}{l}\text { Period/Age } \\
\text { Cohort/Age } \\
\text { Period/Age, Cohort } \\
\text { Cohort/Age, Period }\end{array}$ & $\begin{array}{r}6 \\
13 \\
5 \\
12\end{array}$ & $\begin{array}{c}34 \cdot 5 \ddagger \\
46 \cdot 7 \ddagger \\
3 \cdot 1 \\
15 \cdot 3\end{array}$ & $\begin{array}{c}21 \cdot 5 \dagger \\
36 \cdot 4 \ddagger \\
3 \cdot 6 \\
18 \cdot 4\end{array}$ & $\begin{array}{c}43 \cdot 1 \ddagger \\
31 \cdot 6 \dagger \\
18 \cdot 6 t \\
7 \cdot 0\end{array}$ & $\begin{array}{c}14 \cdot 1^{\star} \\
24 \cdot 9^{\star} \\
7 \cdot 0 \\
17 \cdot 8\end{array}$ \\
\hline
\end{tabular}

significance. Line 4 shows that, in every case, cohort effects were no longer significant after adjustment for age and period. In most cases, secular trends could therefore be explained satisfactorily either by period or cohort effects, and it was not necessary to include both period and cohort effects. Only for Republic of Ireland males were period effects clearly preferable.

The limited evidence available would therefore appear to support period effects in preference to cohort effects for the explanation of Irish mortality trends.

\section{Discussion}

The purpose of this paper is to describe the trends in colorectal cancer in Ireland, north and south, and to put these trends in the context of the mainland Britain trends over the same period. It is not the intention to enter into the continuing debate on the usefulness of particular methods of separating the effects of age, periods or cohort from a vital rate matrix. ${ }^{12}$

As has been indicated elsewhere ${ }^{12}$ the trends are not thought to be attributable to changes in coding and certification practices, especially when the "very old" deaths have been excluded. Any such changes would be expected to have the same effect on males and females. ${ }^{3}$ An alternative may be that changing diagnostic practices could account for the observed trends. This point warrants careful consideration. The most important diagnostic innovation during the period (which may have had greater effects on more proximal colonic tumours) was the introduction of double contrast barium enema in the late 1960s. It is hard to concede that this was the explanation for the rise in colon cancer mortality in Ireland in the late 1960s, when colonic and rectal disease mortality followed downward trends on mainland Britain where diagnostic access presumably increased during a roughly equivalent period. Indeed the near parallelism of the rise in colon cancer mortality north and south in the late 1960s would be difficult to explain on the basis of diagnostic access. It is unlikely that such access diffused at the same rate in the south as in the north of Ireland since, for much of this period, there was no National Health Service in the Republic of Ireland. ${ }^{13}$

These trends would be greatly clarified if accurate local incidence data were available. Some of the decrease in mortality that occurred in the
UK mainland after 1950 has been attributed to improved survival. ${ }^{2}$ Differences in survivorship between small areas have been found elsewhere to underlie geographical mortality differentials, ${ }^{14-16}$ but without high quality incidence data broken down by subsite, ${ }^{17}$ such a premise would be hard to evaluate further in Ireland.

More interesting perhaps, in view of a renewed emphasis on the primary prevention of cancer, are the putative effects of changing exposures to dietary risk factors. It has been contended that the declines in colorectal cancer mortality observed on mainland UK in the 1950s were attributable to a large degree to the healthier diet adopted by most of the population during war rationing 10 years earlier. ${ }^{1218}$ During this period, consumption of meat and fat products decreased and crude fibre intake increased. ${ }^{2}$ In general, it is accepted that dietary factors affect the risks of colonic disease more than rectal disease, ${ }^{19}$ but although the decline in rectal cancer mortality in Ireland seems more consistently to reflect similar mainland declines, the contrast with colon cancer may be significant. The similar falls in Ireland both north and south of the border in the late 1950 s and subsequent rises in the early 1960s do not clearly support the dietary hypothesis expounded above. Whilst changes in the Northern Ireland diet reflected those of the mainland during the war, no such rationing was introduced in the South. Indeed a recent analysis of the 1948 National Food Survey in the Republic of Ireland clearly indicates that intakes of fat and meat products were well above those of UK citizens at that time ( $M$ Crawford, personal communication).

However the weaknesses of such ecological inference in epidemiology are well known. ${ }^{20} 21$ Though a similar anomaly was described in New Zealand, ${ }^{6}$ where excess dietary risks were similar for both Maoris and non-Maoris during a period when colorectal cancer was falling among Maoris and rising among Europeans, it is possible that genetic variation in New Zealand could have accounted for some of the inter population differences in responses to either "risk" or "protective" factors. ${ }^{22}$

The fact that the age-period model was the most statistically parsimonious lends support to the use of a simple graphical plot of age standardised rates to display the data. It is unwise, however, on the basis of such statistical models, to make too far reaching assumptions about the origin of regional or gender variations in period or 
cohort trends. Osmond et al have inferred that the origin lies in dietary practices. ${ }^{3}$ Other factors such as a changing parity distribution may be important ${ }^{1923}$ but have been given scant attention. In view of the growing evidence for cancer as a multistep process at the cellular level ${ }^{24}$ the identification of period effects, traditionally relying on the detection of roughly equivalent changes in log transformed incidence rates across age groups, may be conceptually inadequate. Age may well be an effect modifier. Changes in diet, whether adverse or beneficial, may have different effects on different age groups ${ }^{25}$ or different subsites within the bowel ${ }^{26}$ and may well interact with genetic factors in undiscernible ways. ${ }^{27}$ Exercises such as these can at best be descriptive. The use of statistical analyses of epidemiological data to infer biological processes can be misleading. Even when acting independently, the actions of some carcinogenic factors may fit an additive statistical model, a multiplicative model, or neither. ${ }^{28}$

Trends in colorectal cancer mortality both in Northern Ireland and the Republic of Ireland do not mirror the changes in mainland Britain. In particular, the Irish data are characterised by continuing high male colon cancer mortality rates and only a very recent decline in female colorectal cancer mortality rates. The explanation for these differences must await a more adequate paradigm than ecological inference can provide.

1 Boyle B, Zaridze DG, Smans M. Descriptive epidemiology of colorectal cancer. Int $f$ Cancer 1985; 36: 9-18.

2 McMichael AJ, Potter JD, Hetzel BS. Time trends in colorectal cancer mortality in relation to food and alcohol consumption: United States, United Kingdom, Australia and New Zealand. Int F Epidemiol 1979; 4: 295-303. 3 Osmond C, Gardner MJ, Acheson ED, Adelstein AM. 1951-80. London: OPCS Series DH1.

4 Boyle B, Zaridze DG. Colorectal cancer as a disease of the environment. Ecol Disease 1983; 2: 241-8.

5 Office of Population Censuses and Surveys. Mortality Supplement Series DH1 No 16. London: OPCS, 1984.

6 Smith AH, Pearce NE, Joseph JG. Major colorectal cancer aetiological hypotheses do not explain mortality trends aetiological hypotheses do not explain mortality trends
among Maori and non Maori New Zealanders. Int $\mathcal{J}$ among Maori and non

7 Corridan JP, Moran MA. Trends in lung, stomach, breast and colorectal carcinoma in Ireland. Time trends and an international comparison. Ir $\mathcal{F}$ Med Sci 1984; 153: 374-80.
8 Harkin K, MacMahon B, Doyle JS. Mortality analysis of colorectal carcinoma in Ireland. Time trends and an international comparison. Ir $\mathcal{F}$ Med Sci 1985; 154: 343-7.

9 Waterhouse J, Muir C, Shanmugoratnom K, et al, eds. cancer incidence in five continents. Volume V. Lyon: International Agency for Research on Cancer, 1987.

10 Holford TR. The estimation of age, period and cohort effects for vital rates. Biometrics 1983; 39: 311-24.

11 Breslow NE. Extra Poisson variation on log-linear models. Appl Stat 1984; 33: 38-44.

12 Clayton D, Schifflers E. Models for temporal variation in cancer rates I: Age-period and age-cohort models. Stat Med 1987; 6: 449-67.

13 Barrington R. Health medicine and politics in Ireland 19001970. Dublin: Institute of Public Administration, 1987.

14 Horner R, Chirikus TN. Survivorship differences in geographical comparisons of cancer mortality. An urbanrural analysis. Int 7 Epidemiol 1987; 16: 184-9.

15 Piantadosi S, Byar DP, Gail M. Screening geographic areas for unusual survival experience or stage at diagnosis with application to breast and colon cancer. $\mathcal{J}$ Natl Cancer Inst application to breast

16 Fielding LP, Stewart-Brown S, Blesovsky L, Kearney G. Anastomotic integrity after operations for large bowel cancer: a multi-centre study. $\mathrm{Br}$ Med F 1980; 281: 411-4.

17 Halvorsen TB, Seim E. Tumour site: a prognostic factor in colorectal cancer? A multivariate analysis. Scand $\mathcal{J}$ Gastroenterol 1987; 22: 124-8.

18 McMichael AJ, McCall MG, Hartslorne JM, Woodings TL. Patterns of gastrointestinal cancer in European TL. Patterns of gastrointestinal cancer in European
migrants to Australia: the role of dietary change. Int $\mathcal{f}$ migrants to Australia: the
Cancer 1980; 25: 431-7.

19 McMichael AJ, Potter JD. Diet and colon cancer: integration of descriptive, analytic and metabolic epidemiology. Natl Cancer Inst Monograph 1984; 69: 223-8.

20 Zaridze DG, Muir CS, McMichael AJ. Diet and cancer: value of different types of epidemiological studies. Nutr Cancer 1985; 7: 155-67.

21 Richardson S, Stucker I, Hemon D. Comparison of relative risks obtained in ecological and individual studies; some methodological considerations. Int $\mathcal{F}$ Epidemiol 1987; 16: 111-19.

22 Ferguson LR, Alley PG. Faecal mutagens from population groups within New Zealand at different risk of colorectal cancer. Proceedings of 12th Annual Meeting of the cancer. Proceedings of 12th Annual Meeting of the European Environmental Mutagen Society. In: Mutagens
in our environment. New York: Alan $R$ Liss, 1982: in our

23 McMichael AJ, Potter JD. Do intrinsic sex differences in lower alimentary tract physiology influence the sex-specific risks of bowel cancer and other biliary and intestinal diseases? Am f Epidemiol 1983; 118: 620-7.

24 Farber $E$. The multistep nature of cancer development. Cancer Res 1984; 44: 4217-23.

25 Testa MA, Meigs JW, Flannery JT. Mathematical modelling of cancer incidence rates: linear models of colon cancer in Connecticut. $\mathcal{F}$ Chron Dis 1980; 33: 733-43.

26 Volbecky J, Leduc C, Devroedi G. Sex differences in the changing anatomic distribution of colorectal carcinoma. Cancer 1984; 54: 3065-9.

27 Weiss KM, Schull WJ. Identifying groups at high risk of colorectal cancer. In: Prevention of hereditary large bowel colorectal cancer. In: Prevention of hereditary larg

28 Siemiatycki J, Thomas D. Biological models and statistical interactions: An example from multistage carcinogenesis. Int $\mathcal{Y}$ Epidemiol 1981; 10: 383-7. 